\title{
The effect of CYP2C19 gene polymorphisms on the pharmacokinetics and pharmacodynamics of prasugrel 5-mg, prasugrel 10-mg and clopidogrel 75-mg in patients with coronary artery disease
}

Paul A. Gurbel, Thomas O. Bergmeijer, Udaya S. Tantry, Jurrien M. ten Berg, Dominick J. Angiolillo, Stefan James, Tomas Lindahl, Peter Svensson, Joseph A. Jakubowski, Patricia B. Brown, Suman Duvvuru, Scott Sundseth, Joseph R. Walker, David Small, Brian A. Moser, Kenneth J. Winters and David Erlinge

\section{Linköping University Post Print}

\section{Tweet}

N.B.: When citing this work, cite the original article.

Original Publication:

Paul A. Gurbel, Thomas O. Bergmeijer, Udaya S. Tantry, Jurrien M. ten Berg, Dominick J. Angiolillo, Stefan James, Tomas Lindahl, Peter Svensson, Joseph A. Jakubowski, Patricia B. Brown, Suman Duvvuru, Scott Sundseth, Joseph R. Walker, David Small, Brian A. Moser, Kenneth J. Winters and David Erlinge, The effect of CYP2C19 gene polymorphisms on the pharmacokinetics and pharmacodynamics of prasugrel 5-mg, prasugrel 10-mg and clopidogrel 75-mg in patients with coronary artery disease, 2014, Thrombosis and Haemostasis, (112), 3, 589-597.

http://dx.doi.org/10.1160/TH13-10-0891

Copyright: Schattauer

http://www.schattauer.de/

Postprint available at: Linköping University Electronic Press

http://urn.kb.se/resolve?urn=urn:nbn:se:liu:diva-111270 
The effect of CYP2C19 gene polymorphisms on the pharmacokinetics and

pharmacodynamics of prasugrel 5-mg, prasugrel 10-mg and clopidogrel-75 $\mathrm{mg}$ in patients

with coronary artery disease

Gurbel CYP2C19 genetics in GENERATIONS and FEATHER

Paul A. Gurbel, MD, $\mathrm{PhD}^{1}$; Thomas O. Bergmeijer, $\mathrm{MD}^{2}$; Udaya S. Tantry, $\mathrm{PhD}^{1}$; Jurrien $\mathrm{M}$.

Ten Berg, MD, $\mathrm{PhD}^{2}$; Dominick J. Angiolillo, MD, $\mathrm{PhD}^{3}$; Stefan James, MD, $\mathrm{PhD}^{4}$; Tomas L.

Lindahl, MD, PhD ${ }^{5}$; Peter Svensson, $\mathrm{MD}, \mathrm{PhD}^{6}$; Joseph A. Jakubowski, $\mathrm{PhD}^{7}$; Patricia B.

Brown, BSN, RN ${ }^{7}$; Suman Duvvuru, $\mathrm{PhD}^{7}$; Scott Sundseth, $\mathrm{PhD}^{8}$; Joseph R. Walker, MD ;

David Small, $\mathrm{PhD}^{7}$; Brian A. Moser, $\mathrm{MS}^{7}$; Kenneth J. Winters, $\mathrm{MD}^{7}$; David Erlinge, MD, $\mathrm{PhD}^{10}$

1. Sinai Center for Thrombosis Research, Baltimore, MD, USA

2. Department of Cardiology, St. Antonius Hospital, Nieuwegein, The Netherlands

3. Cardiovascular Research Center at University of Florida College of Medicine Jacksonville, FL, USA

4. Department of Medical Sciences, Cardiology and Uppsala Clinical Research Center, Uppsala University, Sweden

5. Department of Clinical and Experimental Medicine, Linkoping University, Sweden

6. Department of Coagulation Medicine, Lund University, Malmo, Sweden

7. Eli Lilly and Company, Indianapolis, IN, USA

8. Cabernet Pharmaceuticals, Chapel Hill, NC, USA

9. Daiichi Sankyo Pharma Development, Edison, NJ, USA

10. Department of Cardiology, Lund University, Lund, Sweden

\section{Address for Correspondence:}

Paul A. Gurbel, M.D.

Sinai Center for Thrombosis Research,

Cardiac Catheterization Laboratory,

2401 W. Belvedere Ave, Baltimore, MD 21215

Fax: 410-601-9601

Phone: 410-601-9600

E-mail: PGURBEL@LIFEBRIDGEHEALTH.ORG

Word Count: 4,294 
Journal Subject Codes: 


\section{ABSTRACT}

Background: $C Y P 2 C 19$ genotype has been shown to impact response to clopidogrel 75-mg but not prasugrel 10-mg. Here, we assessed effects of CYP2C19 metabolizer status on pharmacokinetics (PK) and pharmacodynamic (PD) responses to prasugrel 5-mg and 10-mg and clopidogrel 75-mg using data from two PK/PD studies in stable CAD patients (GENERATIONS and FEATHER).

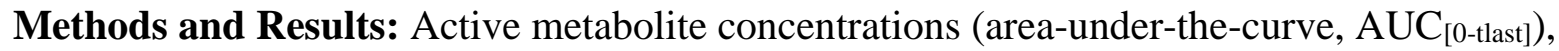
maximum platelet aggregation (MPA) measured by light transmission aggregometry, vasodilator-stimulated phosphoprotein platelet reactivity index, and VerifyNow P2Y12-platelet reactivity units (VN-PRU) were analyzed according to CYP2C19-predicted phenotype (extensive metabolizer [EM; N=154], *2-*8 non-carriers, versus reduced metabolizer [RM; N=41],*2-*8 carriers/*17 non-carriers). $\mathrm{AUC}_{(0 \text {-tlast })}$ was unaffected by metabolizer status for prasugrel 5-mg and 10-mg (geometric mean EM/RM ratios 1.00, 95\% CI:[0.86,1.17], p>0.99; and 0.97, 95\% CI:[0.85,1.12], $\mathrm{p}=0.71$, respectively), but was lowered among reduced metabolizers receiving clopidogrel 75-mg $(1.37,95 \%$ CI: $[1.14,1.65], \mathrm{p}<0.001)$. Platelet reactivity was not significantly affected by CYP2C19 metabolizer status for prasugrel 5-mg, or for prasugrel 10-mg by MPA and VN-PRU, but for clopidogrel 75-mg was significantly higher in reduced metabolizers (all measures $\mathrm{p}<0.01)$. Prasugrel 10-mg showed greater antiplatelet effects versus clopidogrel 75-mg (all comparisons $\mathrm{p}<0.001$ ). Prasugrel 5-mg showed greater antiplatelet effects versus clopidogrel 75-mg in reduced metabolizers (all $\mathrm{p}<0.001$ ), and comparable effects in extensive metabolizers (all $\mathrm{p} \geq 0.37$ ).

Conclusions: In contrast to clopidogrel, prasugrel active metabolite PK was not influenced by CYP2C19 genotype. Antiplatelet effect for prasugrel 10-mg was greater irrespective of 
metabolizer status and for prasugrel 5-mg was greater for reduced metabolizers and comparable for extensive metabolizers versus clopidogrel 75-mg.

Clinical Trial Registration: NCT01107925 and NCT01107912

Keywords: prasugrel, clopidogrel, CYP2C19, platelet reactivity, coronary artery disease 


\section{Introduction}

Clopidogrel and prasugrel are thienopyridine prodrugs that require cytochrome P450 (CYP)mediated conversion to active metabolites that inhibit the $\mathrm{P} 2 \mathrm{Y}_{12}$ receptor. $C Y P 2 C 19$ gene polymorphisms, most importantly the $* 2$ loss-of-function allele, have been associated with alterations in the pharmacodynamics (PD) and clinical efficacy of clopidogrel, but not prasugrel, in patients undergoing percutaneous coronary interventions (PCI). ${ }^{1,2}$ In the TRial to Assess Improvement in Therapeutic Outcomes by Optimizing Platelet InhibitioN with Prasugrel (TRITON)-TIMI 38 study, a significantly reduced rate of the composite efficacy endpoint of cardiovascular death, myocardial infarction, or stroke was demonstrated in prasugrel-treated patients compared to clopidogrel-treated patients with acute coronary syndromes undergoing PCI. ${ }^{3}$ However, there was an increased risk for major bleeding in very elderly (VE, $\geq 75$ years) and low body weight (LBW, $<60 \mathrm{~kg}$ ) patients receiving the prasugrel 10-mg maintenance dose (MD). A lower prasugrel dose was suggested in these patients to reduce the bleeding risk based on population pharmacokinetic (PK) modeling in a TRITON-TIMI 38 substudy. ${ }^{4}$

The GENERATIONS and FEATHER studies compared pharmacokinetic (PK) and PD measures for prasugrel 5-mg and 10-mg and clopidogrel 75-mg in stable coronary artery disease (CAD) patients receiving aspirin. In the GENERATIONS study, maximum platelet aggregation (MPA) in response to $20 \mu \mathrm{M}$ adenosine diphosphate (ADP) for prasugrel 5-mg in VE patients met the primary non-inferiority criterion versus prasugrel $10-\mathrm{mg}$ in non-elderly patients (NE, $\geq 45-<65$ years); platelet inhibition was also significantly greater for prasugrel 5-mg versus clopidogrel 75mg in VE patients ${ }^{5}$. In the FEATHER study, comparing LBW patients $(<60 \mathrm{~kg})$ to higher body weight patients (HBW, $\geq 60 \mathrm{~kg}$ ), prasugrel 5-mg in LBW patients reduced platelet reactivity to a 
similar extent as prasugrel 10-mg in HBW patients, and to a greater extent than clopidogrel 75mg. 6

However, the influence of CYP2C19 genotype on PK and PD response during prasugrel 5-mg treatment, particularly in LBW or VE CAD patients, is unknown. The objective of the current analysis was therefore to investigate the association of CYP2C19 genotype-predicted metabolizer status (primarily extensive metabolizers $[\mathrm{EM}]$ versus reduced metabolizers [RM]) with the PK and PD profiles of prasugrel 5-mg and 10-mg and clopidogrel 75-mg in aspirin-treated stable CAD patients from the GENERATIONS and FEATHER studies. 


\section{Methods}

The primary results, along with detailed descriptions of the methods for both studies, have been presented previously ${ }^{5,6}$; the study design, which was similar for both studies, is shown in Figure 1. In brief, both were international, multicenter, randomized, blinded, active-comparator, crossover studies in patients with stable CAD receiving background aspirin therapy. GENERATIONS $(\mathrm{N}=155)$ and FEATHER $(\mathrm{N}=72)$ were Phase Ib trials. The present analysis included all subjects from GENERATIONS and FEATHER who received at least one dose of study drug, with at least one evaluable PK profile and/or PD measurement post-baseline, and a usable genetic sample.

The impact of $C Y P 2 C 19$ genotype-predicted metabolizer status on PK was tested by assessing predicted metabolizer status relative to the active metabolite area under the concentration-time curve from the time of dosing to the last quantifiable measurement through 4 hours post-dose

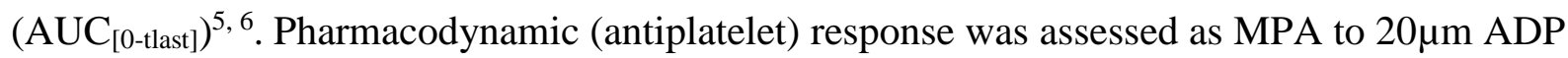
by light transmission aggregometry; vasodilator- stimulated phosphoprotein platelet reactivity index (VASP-PRI); and VerifyNow ${ }^{\circledR}$ P2Y12 reaction units (VN-PRU) at day $12 \pm 2$ of the MD period within each treatment regimen ${ }^{5,6}$. Samples for PD analyses were drawn prior to MD on the last day of each study period, approximately 24 hours after the last MD. The current analysis involved separate comparisons of PK and PD responses primarily between two CYP2C19predicted phenotypes - extensive metabolizers (EM) and reduced metabolizers (RM). Comparisons were performed both within and between treatment groups. PD and PK were assessed as described previously ${ }^{5,6}$.

\section{Genotyping methodology}


Patients participating in the genotyping substudy were consented for the collection and storage of DNA samples for research. Blood samples for testing were obtained at baseline prior to receiving study drug. DNA was extracted from peripheral blood using standard methods. Genotype data was generated using the Drug Metabolizing Enzyme and Transporter Gene (DME/T ${ }^{\mathrm{TM}}$ ) Plus assay system (Affymetrix Inc., Santa Clara, California) at Covance Genomic Laboratories, a CLIA-certified laboratory.

To assess the association of $C Y P 2 C 19$ genetic variants with prasugrel and clopidogrel active metabolite exposure and $\mathrm{PD}$ response, alleles of CYP2C19 previously shown to be involved in the metabolism of the two drugs were classified a-priori according to their predicted metabolizer phenotypes. This classification was defined according to literature-based predictions using the established common consensus or 'star allele' nomenclature (http:// www.cypalleles.ki.se) ${ }^{7}$. For 2-level CYP2C19-predicted phenotypes, EM was defined as *1/*1, *1/*17 or *17/*17; RM was defined as $* 1 / * 2-* 8$ or $* 2-* 8 / * 2-* 8$. For patients with a $* 2-* 8 / * 17$ genotype, predicted metabolizer phenotype was defined as unknown and patients were not analyzed (see supplemental materials $)^{2}$. A 4-level phenotype was defined by taking into account the $* 17$ allele (gain-of-function) and the number of loss-of-function alleles present, and thus further subdividing the RM group into intermediate metabolizer (IM: heterozygous for loss-of-function allele) and poor metabolizers (PM: homozygous for loss-of-function allele) and sub-dividing the extensive metabolizer group into ultrarapid metabolizers (UM: CYP2C19*17 carriers) and extensive metabolizers (labeled as $\mathrm{EM}_{4 \mathrm{~L}}$ to distinguish from extensive metabolizers by 2-level analysis: $* 1 / * 1)($ Supplemental Table 1$)$. Safety was assessed based on overall rates of drugrelated bleeding events summarized by treatment and extensive- versus reduced- metabolizer status. 


\section{Statistical Analysis}

Demographic and baseline characteristics were summarized by CYP2C19-predicted phenotype and by treatment regimen. Categorical variables were compared using the Pearson Chi-square test. Continuous variables were summarized using summary statistics and means were compared using a two sample t-test.

The associations between $C Y P 2 C 19$-predicted phenotypes and PK and PD parameters were tested using linear mixed-effect models, with the outcomes being exposure to each drug's active metabolite $\log \left(\mathrm{AUC}_{[0-\text { tlast }]}\right)$ and platelet function (MPA to $20 \mu \mathrm{M}$ ADP, VASP-PRI, and VNPRU), respectively. The models contained CYP2C19-predicted phenotype as the predictor of main interest and other fixed effects including age ( $<75$ years, $\geq 75$ years) and body weight $(<60$ $\mathrm{kg}, \geq 60 \mathrm{~kg}$ ) cohorts. For PD response, baseline measurement was also included as a covariate. Two-sided $\mathrm{p}$ values were calculated, and a significance threshold of $\mathrm{p}<0.05$ was used for extensive versus reduced metabolizer comparisons within each treatment group. Similar models were used to analyze the CYP2C19 effect by 4-level phenotype (UM/EM $4 \mathrm{~L} / \mathrm{IM} / \mathrm{PM})$.

For the between treatment analyses by CYP2C19-predicted phenotype (EM/RM), linear models for PK and PD responses included the following terms: sequence, period, treatment, age cohort, and body weight cohort as fixed effects and subject as a random effect. For the PD models, baseline measurement was used as an additional covariate. Measurements repeated within a subject were assumed to have compound symmetry correlation structure.

A Fisher's exact test was used to compare the event rates for bleeding between EM and RM groups within each treatment regimen. 


\section{Results}

\section{Patients}

Among 227 total patients who entered the first treatment phase, and 215 who completed all 3 treatment periods, 212 patients from the GENERATIONS $(n=146)$ and FEATHER $(n=66)$ studies had DNA samples available and were included in this pooled pharmacogenetic analysis. CYP2C19-predicted phenotypes could not be assigned for 17 patients ( 16 with $* 2 / * 17$ and 1 with a $* 9 / * 17$ genotype), who were thus excluded from further analysis. Among the remaining 195 patients, 154 were classified as extensive metabolizers and 41 as reduced metabolizers (Supplemental Table 1). There were no statistically significant differences in baseline demographic characteristics between the predicted phenotype groups, although for the RM population mean age was lower, a numerically greater proportion were smokers, and a numerically lower proportion were Caucasian (Table 1).

\section{Pharmacokinetic comparisons}

As shown in Figure 2, there was no significant effect of $C Y P 2 C 19$-predicted phenotype on active metabolite exposure as measured by $\mathrm{AUC}_{(0-\text { tlast }}$ for prasugrel 5-mg (geometric mean [GM] EM/RM ratio: $1.00,95 \% \mathrm{CI}:[0.86,1.17], \mathrm{p}>0.99)$ or prasugrel 10-mg (GM ratio: 0.97, 95\% CI:[0.85,1.12], $\mathrm{p}=0.71)$. In contrast, with clopidogrel 75-mg, reduced metabolizers had significantly lower exposure than extensive metabolizers as evidenced by the elevated EM/RM ratio (GM ratio: $1.37,95 \% \mathrm{CI}:[1.14,1.65], \mathrm{p}<0.001)$.

In reduced metabolizers, active metabolite exposure was significantly greater for both prasugrel 5-mg and 10-mg compared to clopidogrel 75-mg (GM ratios 1.83, [1.56, 2.14], $\mathrm{p}<0.001$; and $4.11,[3.48,4.86], \mathrm{p}<0.0001$, respectively). In reduced metabolizers receiving prasugrel versus 
extensive metabolizers receiving clopidogrel 75-mg, active metabolite exposures remained significantly greater with either prasugrel 5-mg or 10-mg versus clopidogrel 75-mg (GM ratios 1.34, [1.12, 1.59], $\mathrm{p}=0.002$; and 2.97, [2.48, 3.55], $\mathrm{p}<0.001$, respectively). Active metabolite exposures were also significantly greater with prasugrel 5-mg or 10-mg for the combined RM and EM group versus clopidogrel extensive metabolizers (GM ratios 1.33, [1.23, 1.43], p<0.001; and 2.92, $[2.71,3.16], \mathrm{p}<0.001$, respectively) (Table 2).

Assessment of active metabolite exposure by 4-level phenotype (UM/ EM $4 \mathrm{~L} / \mathrm{IM} / \mathrm{PM})$ indicated no statistically significant differences between predicted phenotype groups for prasugrel 5-mg or prasugrel 10-mg; however, for clopidogrel 75-mg, exposure in the IM group was significantly reduced compared to either the UM or EM4L group (see supplemental materials).

\section{Pharmacodynamic comparisons}

For within-treatment comparisons, platelet reactivity was not significantly different between extensive and reduced metabolizers for prasugrel 5-mg when measured by MPA, VASP-PRI, or VN-PRU (Table 3, Figure 3A-C). For prasugrel 10-mg, there were no significant differences between extensive and reduced metabolizers for VN-PRU and MPA; however, platelet reactivity was significantly higher in reduced metabolizers as assessed by VASP-PRI $(\mathrm{p}=0.018)$. For clopidogrel 75-mg, platelet reactivity was significantly higher for reduced metabolizers compared to extensive metabolizers for all measures: MPA $(\mathrm{p}=0.006)$, VASP-PRI $(\mathrm{p}<0.001)$ and VN-PRU ( $=0.001)$.

For comparisons between treatments, platelet reactivity was significantly lower in patients receiving prasugrel 10-mg compared to clopidogrel 75-mg, irrespective of metabolizer phenotype (Table 2, $\mathrm{p}<0.001$ for all comparisons). In reduced metabolizers, prasugrel 5-mg resulted in lower platelet reactivity compared to clopidogrel $75-\mathrm{mg}(\mathrm{p}<0.001)$, while in extensive 
metabolizers responses were comparable for both treatments. Reduced metabolizers receiving prasugrel 5-mg had higher platelet reactivity compared to extensive metabolizers receiving clopidogrel 75 -mg when determined by MPA $(\mathrm{p}=0.025)$, but this difference was not significant with VASP-PRI or VN-PRU. Platelet reactivity in the combined RM and EM group while receiving prasugrel 5-mg was not significantly different compared to the EM group while receiving clopidogrel 75-mg (Table 2).

When PD results were assessed by 4-level analysis (see supplemental materials), there were no significant effects observed across assays between the UM, EM4L, and IM groups with prasugrel 5-mg. For prasugrel 10-mg, there were no significant differences by metabolizer group for MPA or VN-PRU; however, VASP-PRI was significantly lower in the IM versus the UM group. For clopidogrel 75-mg, platelet reactivity was significantly greater for the IM group versus either $\mathrm{UM}$ or $\mathrm{EM}_{4 \mathrm{~L}}$ groups across all 3 platelet function tests (all $\mathrm{p}<0.05$ ). The PM group was not analyzed due to the low number of patients $(n=3)$.

\section{Safety and Tolerability}

Rates of treatment-related bleeding events (mainly mild bruising) were similar between extensive and reduced metabolizers within each treatment group, occurring for prasugrel 5-mg in 26/155 extensive metabolizers (16.8\%) and 7/41 reduced metabolizers (17.1\%), for prasugrel 10$\mathrm{mg}$ in 49/156 extensive metabolizers (31.4\%) and 13/42 reduced metabolizers (31.0\%), and for clopidogrel 75-mg in 25/154 extensive metabolizers (16.2\%) and 6/40 reduced metabolizers $(15.0 \%)$ (extensive versus reduced metabolizers, all comparisons $\mathrm{p}>0.05)$. 


\section{Discussion}

We found that the antiplatelet effect of prasugrel 10-mg was greater than that of clopidogrel 75mg irrespective of $C Y P 2 C 19$-predicted metabolizer status, and that for prasugrel 5-mg, the antiplatelet effect was greater versus clopidogrel 75-mg in reduced metabolizers. This finding is relevant for daily practice, because previous studies have demonstrated that the efficacy of clopidogrel is strongly influenced by $C Y P 2 C 19$ polymorphisms. ${ }^{8}$ While $C Y P 2 C 19$ also contributes to prasugrel metabolism, there is no indication of a clinically relevant reduction in antiplatelet effect based on CYP2C19-predicted metabolizer status. To our knowledge, this is the first report to describe the effect of $C Y P 2 C 19$-predicted metabolizer status during therapy with prasugrel 5-mg.

One strength of our analysis was assessing effects of $C Y P 2 C 19$-predicted metabolizer status in parallel on both active metabolite exposure and platelet function, as measured by 3 different platelet reactivity tests. Our findings that both prasugrel 5-mg and 10-mg resulted in higher active metabolite exposure compared to clopidogrel 75-mg, irrespective of $C Y P 2 C 19$-predicted phenotype, is consistent with previous studies investigating the effect of prasugrel $10-\mathrm{mg}^{1,9}$. Also consistent with previous findings, clopidogrel active metabolite exposure was significantly lower in reduced metabolizers compared to extensive metabolizers. ${ }^{2,9}$ Notably, the overall prevalence of specific genotypes in this study population was similar to previous reports describing primarily Caucasian populations, and there were no significant differences in patient demographic characteristics between the EM and RM predicted phenotype groups.

In the present analysis we also examined results by 4-level predicted phenotype. The 2-level phenotype effectively compares loss-of-function allele carriers versus non-carriers, which adds to the underlying power for the analysis, but provides less information on the impact of certain 
specific mutations. In particular, 2-level classification does not take into account the *17 gain-offunction allele, nor does it account for the effects of carrying 1 versus 2 copies of the $* 2$ allele. Notably, in the 4-way analysis, despite reasonable sample sizes, there were no significant differences noted between patients with $* 17 / * 2-* 8$ non-carrier and $* 1 / * 1$ genotypes for PK or PD response for prasugrel or clopidogrel, suggesting that $* 17$ has a more limited impact than the loss-of-function alleles. In the present study, for both the 2-level and 4-level analyses patients with genotypes with unknown impact on antiplatelet drug response were excluded; those were primarily patients with both a loss-of-function and a gain-of-function allele (ie, $* 2 / * 17 ; \mathrm{n}=17$ ). Finally, the 2-way analysis also combined patients carrying 1 and 2 copies of the loss-of-function allele; however, as only 3 patients were $* 2-* 8 / * 2-* 8$, this group was too small in number for meaningful assessment even in 4-way analysis in this study. Nonetheless, in previous publications the $* 2 / * 2$ genotype - although present in only 2-3\% of the Caucasian population showed a strong correlation with worse clinical outcome, like stent thrombosis, in patients using clopidogrel after PCI .

In 2 recent studies, increased rates of high on-treatment platelet reactivity measured by VASPPRI were found in $* 2$ carriers receiving prasugrel $10-\mathrm{mg}^{10,11}$. In those studies, a 3-way classification scheme was used defining poor metabolizers (*2 carrier/*17 non-carrier), intermediate metabolizers ( $* 2$ carrier $/ * 17$ carrier and $* 2$ non-carrier $/ * 17$ non-carrier), and ultrametabolizers $(* 2$ non-carrier $/ * 17$ carrier). Despite the differences in classification, which hamper a direct comparison of study results, in our analysis platelet reactivity as measured by VASP-PRI was significantly higher in the IM group $(* 2-* 8$ carrier/*1 carrier, largely similar to the poor metabolizer classification in the reports of Grosdidier et al. ${ }^{11}$ and Cuisset et al. ${ }^{10}$ ) compared to the UM group $(* 2-* 8$ non-carrier $/ * 17$ carrier) in patients treated with prasugrel 10 - 
mg. However, this finding was not supported by differences in prasugrel active metabolite levels between extensive and reduced metabolizers. Also, no significant differences were found between extensive and reduced metabolizers in MPA or VN-PRU for prasugrel 10-mg, nor in any PD measure following treatment with prasugrel 5-mg. Therefore, the mechanism and relevance of this isolated finding of higher platelet reactivity based on VASP-PRI results in prasugrel 10-mg IM patients remains uncertain.

One limitation of our analysis was the relatively small number of patients assessed. However, it should be noted that the crossover study design is advantageous in assessing the impact of metabolizer status, as patient-specific differences in metabolism that are not accounted for by CYP2C19 prediction are controlled for, since the same patients receive each treatment. Although this analysis was not powered to assess clinical outcomes, adverse event rates for minor bleeding were similar between extensive and reduced metabolizers during each treatment period.

\section{Conclusions}

In our study, prasugrel active metabolite exposure was not influenced by CYP2C19-predicted metabolizer status in patients with stable CAD. In contrast, clopidogrel active metabolite exposure was significantly reduced in patients carrying the loss-of-function allele. Prasugrel 10$\mathrm{mg}$ was associated with a lower platelet reactivity compared to clopidogrel 75-mg, irrespective of CYP2C19-predicted metabolizer status. Prasugrel 5-mg was associated with lower platelet reactivity compared to clopidogrel $75-\mathrm{mg}$ in reduced metabolizers, whereas no significant difference in platelet reactivity was observed compared to clopidogrel in extensive metabolizers. 


\section{Acknowledgements}

Keri Poi (Eli Lilly and Company) and Thomas Melby (inVentiv Health Clinical) were involved in editing this manuscript.

Funding Sources: This study was funded by Daiichi Sankyo Company, Ltd. and Eli Lilly and Company.

\section{Disclosures}

Dr. Gurbel has received research funding, consultation fees and/or honoraria from AstraZeneca, Daiichi Sankyo Company, Ltd. and Eli Lilly and Company, Pozen, Bayer Healthcare, SanofiAventis, CSL Pharmaceuticals, Accumetrics, Nanosphere and Haemoscope and Honoraria from Merck, Daiichi Sankyo Company, Ltd. and Eli Lilly and Company, Boerhinger Ingleheim, Johnson and Johnson, AstraZeneca, Discovery Channel. Dr. Angiolillo has received honoraria for lectures from AstraZeneca, Bristol-Myers Squibb, Daiichi Sankyo Company, Ltd. and Eli Lilly and Company, and Sanofi-Aventis; has received consulting fees from Abbott Vascular, Accumetrics, Arena Pharmaceuticals, AstraZeneca, Bristol-Myers Squibb, Daiichi Sankyo Company, Ltd. and Eli Lilly and Company, Novartis, Portola, Sanofi-Aventis and The Medicines Company; and has received research grants from Accumetrics, AstraZeneca, Bristol-Myers Squibb, Daiichi Sankyo Company, Ltd. and Eli Lilly and Company, Eisai, Evolva, GlaxoSmithKline, Otsuka, Portola, Sanofi-Aventis, and The Medicines Company. Dr. Tantry has received honoraria for lectures and travel support from Accumetrics. Dr. James has received institutional research grants and honoraria from AstraZeneca, Eli Lilly and Company, Merck and Bristol-Myers Squibb, fees for being an advisory board member for AstraZeneca, Eli Lilly and 
Company, and Merck; and honoraria only from The Medicines Company. Dr. Lindahl has received speaker's fees from Boehringer Ingelheim, Octapharma, Leo Pharma and Roche Diagnostics; has served as an advisory board member for Boehringer Ingelheim and BristolMeyer-Squibb, and served as a member of the board of Medirox and Nordic Haemostasis. Dr Svensson has received speaker's fees from Bayer, Boehringer Ingelheim, Octapharma, and Roche Diagnostics and has served as an advisory board member for Boehringer Ingelheim, Bristol-Meyer-Squibb, and Pfizer. Dr. Erlinge has received fees for being a speaker from Daiichi Sankyo Company, Ltd. and Eli Lilly and Company, AstraZeneca, Sanofi-Aventis and Accumetrics and for being an advisory board member for AstraZeneca, Eli Lilly and Company, and Merck. Drs. Ten Berg and Bergmeijer had no relevant disclosures.

\section{P.B. Brown, B.A. Moser, J.A. Jakubowski, D.S. Small, S. Duvvuru, and K.J. Winters are} employees and minor shareholders of Eli Lilly and Company.

J. Walker is an employee and minor shareholder of Daiichi Sankyo Company, Ltd.

S.S. Sundseth has received consulting fees from Eli Lilly and Company. 


\section{References}

(1) Mega JL, Close SL, Wiviott SD, Shen L, Hockett RD, Brandt JT et al. Cytochrome P450 genetic polymorphisms and the response to prasugrel: relationship to pharmacokinetic, pharmacodynamic, and clinical outcomes. Circulation. 2009 May 19; 119(19):2553-60.

(2) Varenhorst C, James S, Erlinge D, Brandt JT, Braun OO, Man M et al. Genetic variation of CYP2C19 affects both pharmacokinetic and pharmacodynamic responses to clopidogrel but not prasugrel in aspirin-treated patients with coronary artery disease. Eur Heart J. 2009 July; 30(14):1744-52.

(3) Wiviott SD, Braunwald E, McCabe CH, Montalescot G, Ruzyllo W, Gottlieb S et al. Prasugrel versus clopidogrel in patients with acute coronary syndromes. N Engl J Med. 2007 November 15; 357(20):2001-15.

(4) Riesmeyer JS, Salazar DE, Weerakkody GJ, Ni L, Wrishko RE, Ernest CS et al. Relationship Between Exposure to Prasugrel Active Metabolite and Clinical Outcomes in the TRITON-TIMI 38 Substudy. J Clin Pharmacol. 2012 June; 52(6):789-97.

(5) Erlinge D, Gurbel PA, James S, Lindahl TL, Svensson P, ten Berg J et al. Prasugrel 5-mg in the very elderly attenuates platelet inhibition but maintains non-inferiority to prasugrel $10-\mathrm{mg}$ in nonelderly patients: The GENERATIONS trial, a pharmacodynamic and pharmacokinetic study in stable coronary artery disease patients. J Am Coll Cardiol. 2013; In press.

(6) Erlinge D, ten Berg J, Foley D, Angiolillo DJ, Wagner H, Brown PB et al. Reduction in platelet reactivity with prasugrel $5 \mathrm{mg}$ in low-body-weight patients is noninferior to prasugrel $10 \mathrm{mg}$ in 
higher-body-weight patients: results from the FEATHER trial. J Am Coll Cardiol. 2012 November $13 ; 60(20): 2032-40$.

(7) Sim SC, Ingelman-Sundberg M. The Human Cytochrome P450 (CYP) Allele Nomenclature website: a peer-reviewed database of CYP variants and their associated effects. Hum Genomics. 2010 April; 4(4):278-81.

(8) Mega JL, Close SL, Wiviott SD, Shen L, Hockett RD, Brandt JT et al. Cytochrome p-450 polymorphisms and response to clopidogrel. N Engl J Med. 2009 January 22; 360(4):354-62.

(9) Mega JL, Close SL, Wiviott SD, Shen L, Walker JR, Simon T et al. Genetic variants in ABCB1 and CYP2C19 and cardiovascular outcomes after treatment with clopidogrel and prasugrel in the TRITON-TIMI 38 trial: a pharmacogenetic analysis. Lancet. 2010 October 16; 376(9749):1312-9.

(10) Cuisset T, Loosveld M, Morange PE, Quilici J, Moro PJ, Saut N et al. CYP2C19*2 and *17 alleles have a significant impact on platelet response and bleeding risk in patients treated with prasugrel after acute coronary syndrome. JACC Cardiovasc Interv. 2012 December; 5(12):1280-7.

(11) Grosdidier C, Quilici J, Loosveld M, Camoin L, Moro PJ, Saut N et al. Effect of CYP2C19*2 and *17 Genetic Variants on Platelet Response to Clopidogrel and Prasugrel Maintenance Dose and Relation to Bleeding Complications. Am J Cardiol. 2013 April 1; 111(7):985-90. 


\section{Legends}

Figure 1. Study design

Figure 2. Active metabolite exposure by treatment and CYP2C19 metabolizer status.

$\mathrm{AUC}_{(0-\text {-last })}=$ area under the concentration-time curve from time of dosing to last quantifiable concentration through 4 hours postdose; Clop = clopidogrel; EM = extensive metabolizers; GM = geometric mean; Pras $=$ prasugrel $; \mathrm{RM}=$ reduced metabolizers

Figure 3. Pharmacodynamic response to prasugrel 5-mg and 10-mg and clopidogrel 75-mg according to CYP2C19 metabolizer status as measured by (A) VASP-PRI (\%) (B) VN-PRU and $(\mathrm{C})$ MPA by light transmission aggregometry. $\mathrm{ADP}=$ adenosine diphosphate; Clop $=$ clopidogrel; EM = extensive metabolizers; LSM Diff: = least squares mean difference; MPA = maximum platelet aggregation measured by light transmission aggregometry; RM = reduced metabolizers; Pras = prasugrel; VASP-PRI = vasodilator- stimulated phosphoprotein platelet reactivity index; VN-PRU $=$ VerifyNow $\mathrm{P} 2 \mathrm{Y} 12$ reaction units 
Table 1. Patient demographic characteristics according to metabolizer status

\begin{tabular}{lccc}
\hline Measure & EM (N=154) & RM (N=41) & p-value \\
\hline Age & $66.2 \pm 10.7$ & $62.7 \pm 11.8$ & NS \\
Weight & $83.8 \pm 19.0$ & $85.6 \pm 18.3$ & $\mathrm{NS}$ \\
BMI & $28.5 \pm 5.6$ & $28.7 \pm 5.1$ & $\mathrm{NS}$ \\
Male & $103(66.9 \%)$ & $28(68.3 \%)$ & $\mathrm{NS}$ \\
Smoking status & $32(20.8 \%)$ & $13(31.7 \%)$ & $\mathrm{NS}$ \\
Race (Caucasian) & $147(95.5 \%)$ & $36(87.8 \%)$ & $\mathrm{NS}$ \\
Baseline MPA to & $77.3 \pm 9.3$ & & $\mathrm{NS}$ \\
20 $\mu M$ ADP & & $78.8 \pm 9.0$ & \\
\hline
\end{tabular}

$\mathrm{BMI}=$ body mass index MPA = median platelet aggregation $; \mathrm{ADP}=$ adenosine diphosphate;

$\mathrm{EM}=$ extensive metabolizer; RM = reduced metabolizer; NS = non-significant. Values reported for prasugrel $10 \mathrm{mg}$ dosing period. For prasusgrel $5 \mathrm{mg}$ and clopidogrel $75 \mathrm{mg}, \mathrm{RM}$ (both $\mathrm{N}=40$ ), values varied slightly; however all p-values were non-significant. 
Table 2. Pharmacokinetic and pharmacodynamic differences between treatment groups

\begin{tabular}{|c|c|c|c|c|c|c|c|c|}
\hline \multirow[b]{2}{*}{ Comparison } & \multicolumn{2}{|c|}{ AM-AUC } & \multicolumn{2}{|c|}{ VASP-PRI (\%) } & \multicolumn{2}{|l|}{ VN-PRU } & \multicolumn{2}{|c|}{ MPA (\%) } \\
\hline & $\begin{array}{l}\text { LSM Ratio } \\
\text { (95\% Cl) }\end{array}$ & P-value & $\begin{array}{l}\text { LSM Difference } \\
\qquad(95 \% \mathrm{CI})\end{array}$ & P-value & $\begin{array}{l}\text { LSM Difference } \\
\qquad(95 \% \mathrm{Cl})\end{array}$ & P-value & $\begin{array}{l}\text { LSM Difference } \\
\qquad(95 \% \mathrm{Cl})\end{array}$ & P-value \\
\hline $\begin{array}{l}\text { Pras 5-mg RM vs } \\
\text { Clop } 75 \text { RM }\end{array}$ & $\begin{array}{c}1.83 \\
(1.56,2.14)\end{array}$ & $<0.001$ & $\begin{array}{c}-16.34 \\
(-22.71,-9.96)\end{array}$ & $<0.001$ & $\begin{array}{c}-65.15 \\
(-85.86,-44.43)\end{array}$ & $<0.001$ & $\begin{array}{c}-12.67 \\
(-17.69,-7.65)\end{array}$ & $<0.001$ \\
\hline $\begin{array}{l}\text { Pras 10-mg RM vs } \\
\text { Clop } 75 \text { RM }\end{array}$ & $\begin{array}{c}4.11 \\
(3.48,4.86)\end{array}$ & $<0.001$ & $\begin{array}{c}-36.30 \\
(-43.28,-29.31)\end{array}$ & $<0.001$ & $\begin{array}{c}-136.42 \\
(-159.55,113.29)\end{array}$ & $<0.001$ & $\begin{array}{c}-22.00 \\
(-27.39,-16.61)\end{array}$ & $<0.001$ \\
\hline $\begin{array}{l}\text { Pras 5-mg EM vs } \\
\text { Clop EM }\end{array}$ & $\begin{array}{c}1.33 \\
(1.22,1.44)\end{array}$ & $<0.001$ & $\begin{array}{c}0.95 \\
(-2.37,4.26)\end{array}$ & 0.58 & $\begin{array}{c}-1.72 \\
(-11.47,8.03)\end{array}$ & 0.73 & $\begin{array}{c}-0.92 \\
(-2.92,1.08)\end{array}$ & 0.37 \\
\hline $\begin{array}{l}\text { Pras 10-mg EM vs } \\
\text { Clop EM }\end{array}$ & $\begin{array}{c}2.91 \\
(2.67,3.16)\end{array}$ & $<0.001$ & $\begin{array}{c}-23.12 \\
(-26.40,-19.84)\end{array}$ & $<0.001$ & $\begin{array}{c}-95.21 \\
(-105.01,-85.41)\end{array}$ & $<0.001$ & $\begin{array}{c}-12.4 \\
(-14.43,-10.42)\end{array}$ & $<0.001$ \\
\hline $\begin{array}{l}\text { Pras 5-mg RM vs } \\
\text { Clop } 75 \text { EM }\end{array}$ & $\begin{array}{c}1.34 \\
(1.12,1.59)\end{array}$ & 0.002 & $\begin{array}{c}-0.82 \\
(-8.21,6.57)\end{array}$ & 0.82 & $\begin{array}{c}-24.41 \\
(-48.91,0.08)\end{array}$ & 0.051 & $\begin{array}{c}-5.84 \\
(-10.91,-0.78)\end{array}$ & 0.025 \\
\hline
\end{tabular}




\begin{tabular}{|c|c|c|c|c|c|c|c|c|}
\hline $\begin{array}{l}\text { Pras } 10-\mathrm{mg} \text { RM vs } \\
\text { Clop } 75 \text { EM }\end{array}$ & $\begin{array}{c}2.97 \\
(2.48,3.55)\end{array}$ & $<0.001$ & $\begin{array}{c}-21.48 \\
(-29.28,-13.68)\end{array}$ & $<0.001$ & $\begin{array}{c}-97.61 \\
(-124.13,-71.08)\end{array}$ & $<0.001$ & $\begin{array}{c}-15.21 \\
(-20.60,-9.82)\end{array}$ & $<0.001$ \\
\hline Pras 5-mg EM & 1.33 & $<0.001$ & -0.17 & 0.91 & -6.58 & 0.17 & -1.60 & 0.11 \\
\hline +RM vs Clop EM & $(1.23,1.43)$ & & $(-3.26,2.92)$ & & $(-15.90,2.74)$ & & $(-3.55,0.35)$ & \\
\hline Pras 10-mg EM & 2.93 & $<0.001$ & -23.20 & $<0.001$ & $-95.22(-104.75,-$ & $<0.001$ & -12.61 & $<0.001$ \\
\hline +RM vs Clop EM & $(2.71,3.16)$ & & $(-26.31,-20.08)$ & & $85.69)$ & & $(-14.58,-10.63)$ & \\
\hline
\end{tabular}

$\mathrm{AM}-\mathrm{AUC}=$ active metabolite area under the curve $\mathrm{CI}=$ confidence interval; $\mathrm{Clop}=$ clopidogrel $; \mathrm{EM}=$ extensive metabolizers; $\mathrm{LSM}=$ least-squares mean; MPA = maximum platelet aggregation to $20 \mu \mathrm{M}$ adenosine diphosphate Pras $=$ prasugrel; $\mathrm{RM}=$ reduced metabolizers; VASP-PRI = vasodilator-associated stimulated phosphoprotein platelet reactivity index; VN-PRU = VerifyNow P2Y12 reaction units. 
Table 3. Pharmacodynamic response as measured by light transmission aggregometry, VASP and VerifyNow Assays

\begin{tabular}{|c|c|c|c|c|c|}
\hline & & LS Mean (SE) & LS Mean (SE) & LS Mean $(95 \% \mathrm{Cl})$ & \\
\hline & & EM & RM & EM-RM & P-value \\
\hline & Pras 5-mg & $38.97(2.22)$ & $40.03(3.53)$ & $-1.06(-7.86,5.74)$ & 0.76 \\
\hline VASP-PRI & & & & & \\
\hline & Pras 10-mg & $18.42(1.84)$ & $25.18(2.97)$ & $-6.76(-12.34,-1.18)$ & 0.018 \\
\hline & Clop 75-mg & $45.23(2.33)$ & $60.21(3.75)$ & $-14.97(-22.04,-7.90)$ & $<0.001$ \\
\hline & Pras 5-mg & $151.67(7.08)$ & $134.91(11.23)$ & $16.76(-4.63,38.15)$ & 0.124 \\
\hline VN-PRU & Pras 10-mg & $65.50(6.51)$ & $74.88(10.45)$ & $-9.38(-28.99,10.24)$ & 0.35 \\
\hline & Clop 75-mg & $169.90(7.37)$ & $214.27(11.74)$ & $-44.37(-66.8,-21.95)$ & 0.001 \\
\hline & Pras 5-mg & $53.45(1.52)$ & $49.21(2.38)$ & $4.25(-0.35,8.84)$ & 0.070 \\
\hline MPA (\%) & Pras 10-mg & 42.35 (1.39) & $40.86(2.22)$ & $1.49(-2.70,5.68)$ & 0.48 \\
\hline & Clop 75-mg & $56.28(1.57)$ & $63.04(2.52)$ & $-6.76(-11.52,-2.01)$ & 0.006 \\
\hline
\end{tabular}

LS Mean = Least-squares mean; $\mathrm{SE}=$ standard error of the mean; $\mathrm{CI}=$ confidence interval; EM = extensive metabolizers; RM = reduced metabolizers; Pras = prasugrel; Clop = clopidogrel; VASP-PRI = vasodilator-associated stimulated phosphoprotein platelet reactivity index; VNPRU = VerifyNow P2Y12 platelet reaction units; MPA = maximum platelet aggregation to 20 $\mu \mathrm{M}$ ADP; ADP = adenosine diphosphate 
Figure 1. Study design.

Aspirin Run-in

Period

Study Drug Treatment Phase

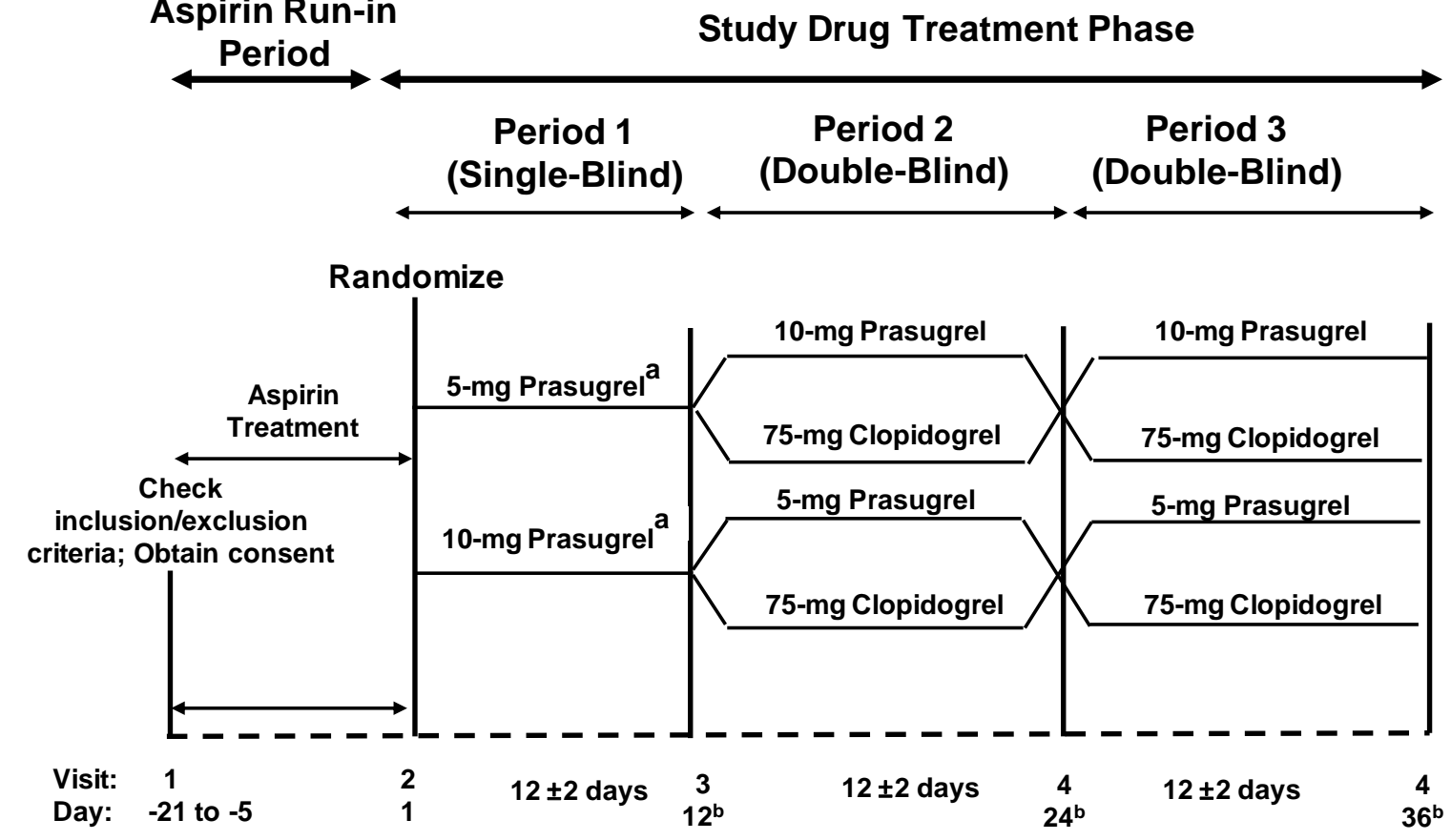

a Randomization to a treatment sequence occurred at Visit 2. During Period 1, very elderly patients (GENERATIONS) or low body weight patients (FEATHER) received prasugrel 5-mg, while non-elderly or high body weight patients received prasugrel 10-mg.

${ }^{\mathrm{b}}$ Minimum of 10 days and maximum of 14 days between visits. 
Figure 2. Active metabolite exposure by treatment and CYP2C19 metabolizer status

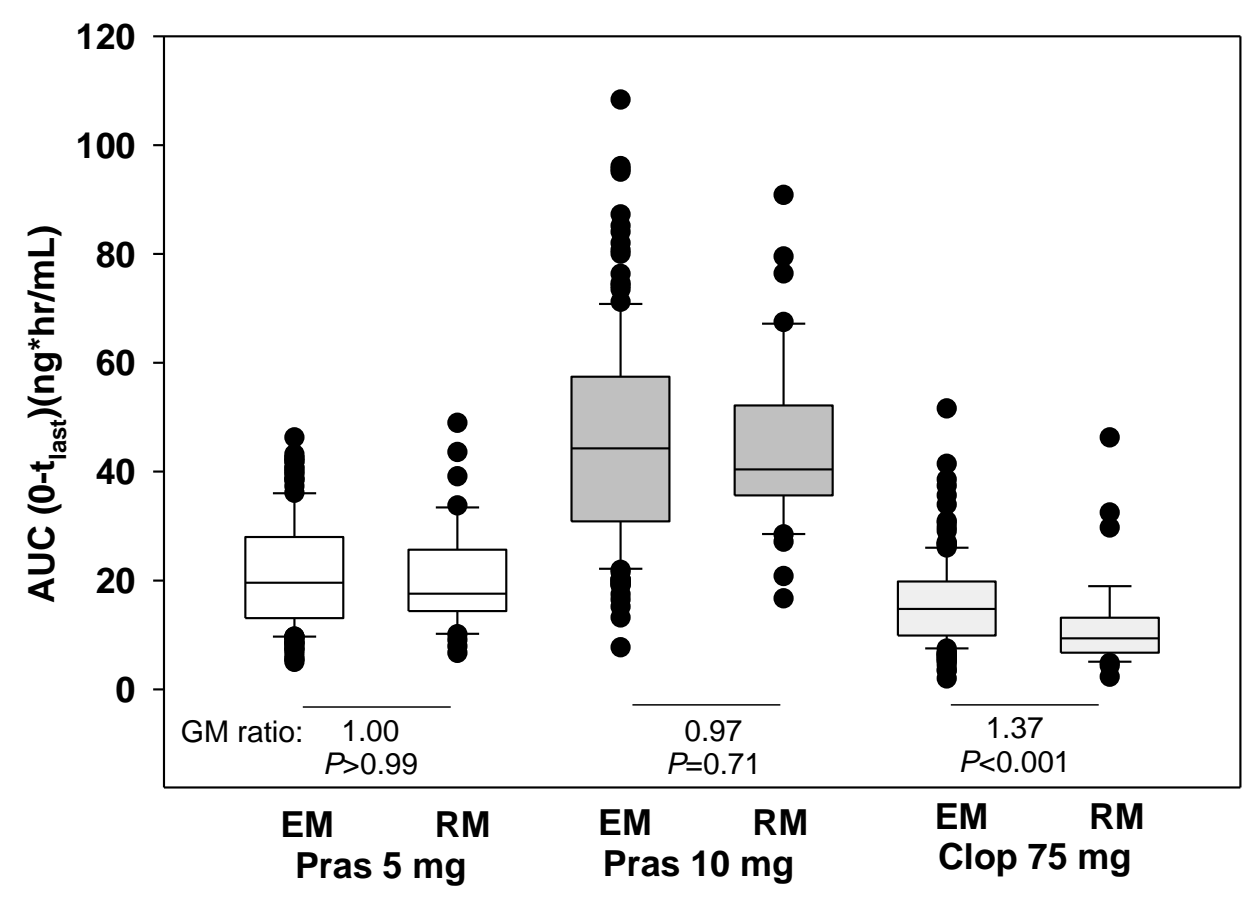


Figure 3. Pharmacodynamic response to prasugrel 5-mg and 10-mg and clopidogrel 75-mg according to CYP2C19 metabolizer status as measured by (A) VASP-PRI (\%) (B) VN-PRU and (C) MPA by light transmission aggregometry.

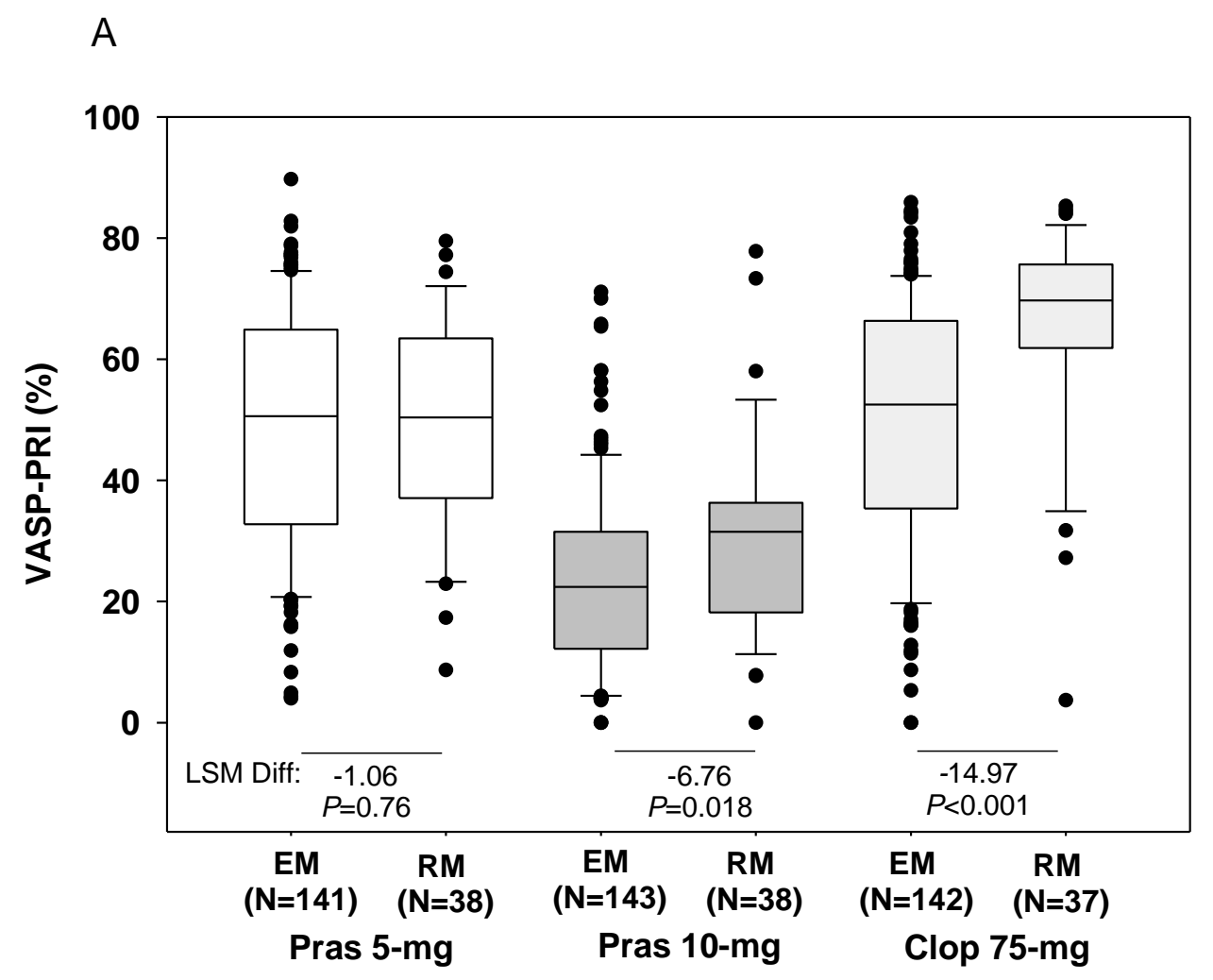


B

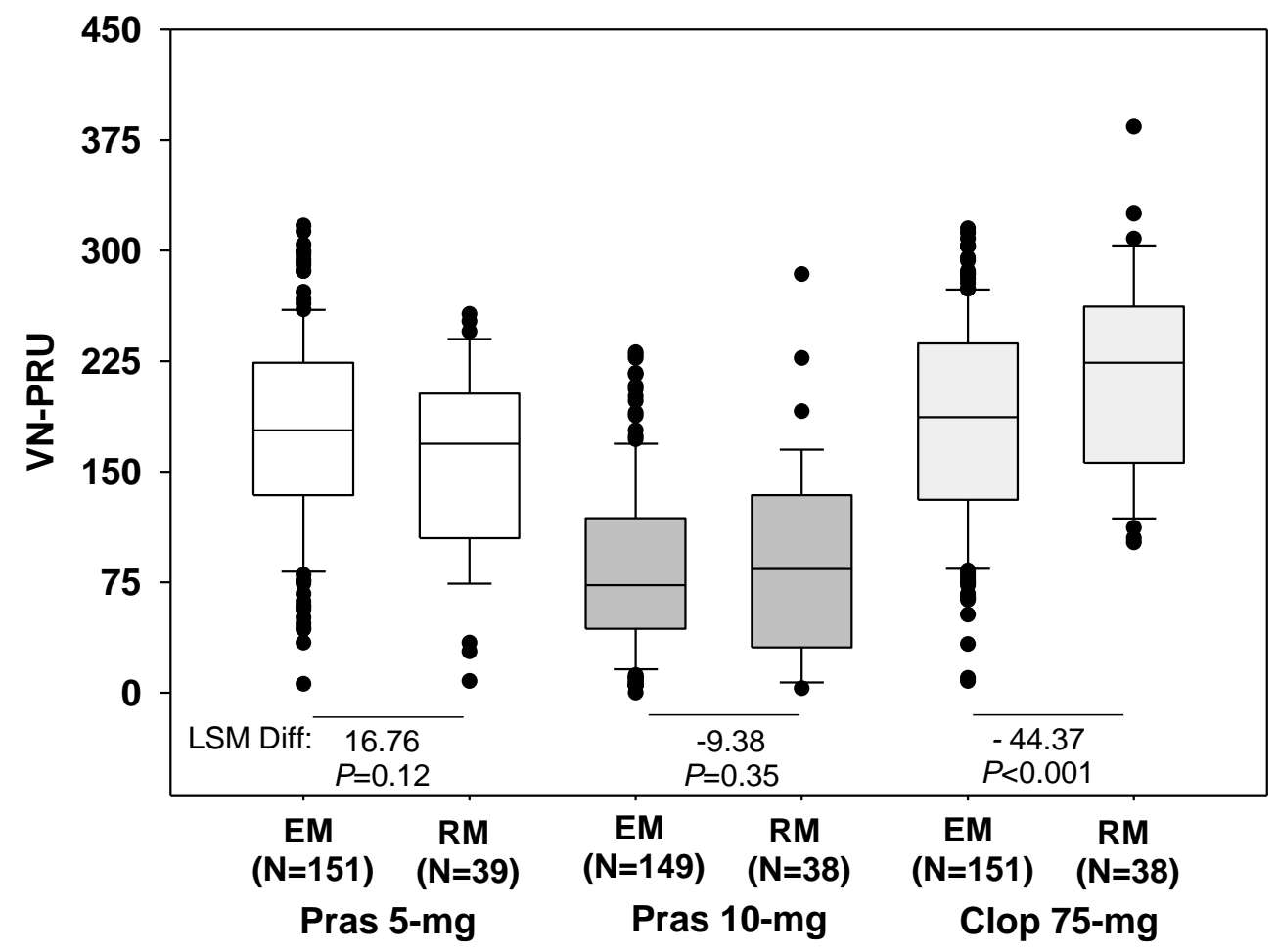

C

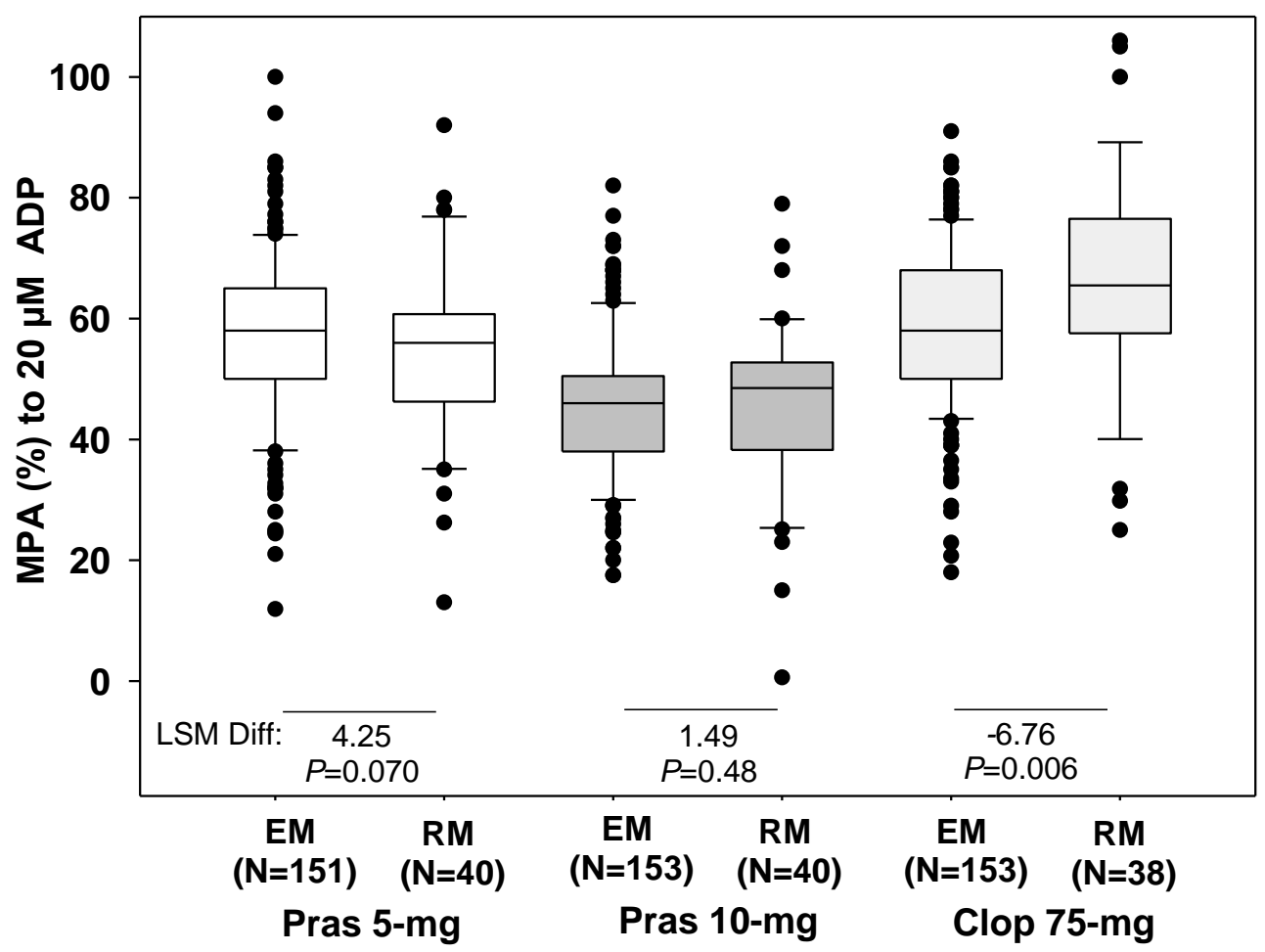


Supplementary Materials

Supplemental Table 1. Definition and frequency of CYP2C19 genotypes by predicted phenotype and treatment (PD population)

\begin{tabular}{|c|c|c|c|c|c|c|}
\hline & & CYP2C19 & Pras 5-mo & Pras 10-mg & Clon 75-mg & Total \\
\hline Predicte & & Genotype & $(n=211)$ & $(n=211)$ & $(n=211)$ & $(n=212)^{*}$ \\
\hline phenoty & & & n (\%) & n $(\%)$ & n $(\%)$ & n $(\%)$ \\
\hline 2-Level & 4-Level & & & & & \\
\hline EM & UM & $* 17 / * 17$ & $16(7.6)$ & $16(7.6)$ & $16(7.6)$ & $16(7.6)$ \\
\hline & & $* 1 / * 17$ & 42 (19.9) & $42(19.9)$ & 42 (19.9) & $42(19.8)$ \\
\hline & EM$_{4 L}$ & $* 1 / * 1$ & $96(45.5)$ & $96(45.5)$ & $96(45.5)$ & $96(45.3)$ \\
\hline $\mathbf{R M}$ & & $* 1 / * 2$ & $34(16.1)$ & $35(16.6)$ & $34(16.1)$ & $35(16.5)$ \\
\hline & IM & $* 1 / * 8$ & $3(1.4)$ & $3(1.4)$ & $3(1.4)$ & $3(1.4)$ \\
\hline & PM & $* 2 / * 2$ & $2(1.0)$ & $2(1.0)$ & $2(1.0)$ & $2(0.9)$ \\
\hline & & $* 2 / * 3$ & $1(0.5)$ & $1(0.5)$ & $1(0.5)$ & $1(0.5)$ \\
\hline Unknow & & $* 2 / * 17$ & $16(7.6)$ & $15(7.1)$ & $16(7.6)$ & $16(7.6)$ \\
\hline & & $* 9 / * 17$ & $1(0.5)$ & $1(0.5)$ & $1(0.5)$ & $1(0.5)$ \\
\hline
\end{tabular}

*Note that all patients may not be identical between treatment groups. Abbreviations: PD = pharmacodynamic $;$ Pras=prasugrel; Clop=clopidogrel; $\mathbf{n = n u m b e r}$ of patients; $\mathbf{E M}=$ extensive metabolizers (2-level); $\mathrm{RM}=$ reduced metabolizers (2-level); $\mathrm{UM}=$ 
ultrametabolizers (4-level); EM$_{4 \mathrm{~L}}=$ extensive metabolizers by 4-level analysis; $\mathrm{IM}=$ intermediate metabolizers (4-level); $P M=$ poor metabolizers (4-level) 
Figure S1. Pharmacokinetic response according four level CYP2C19-predicted metabolizer status. Between predicted metabolizer group comparisons statistical significance $p \geq 0.05$ unless shown on figure. $\mathrm{AUC}_{(0-\text { tlast })}=$ area under the curve from time 0 to last measure; Pras = prasugrel; Clop = clopidogrel; $\mathrm{UM}=$ ultrametabolizers; $\mathrm{EM}$ = extensive metabolizers; $\mathrm{IM}=$ intermediate metabolizers; $\mathrm{PM}=$ poor metabolizers

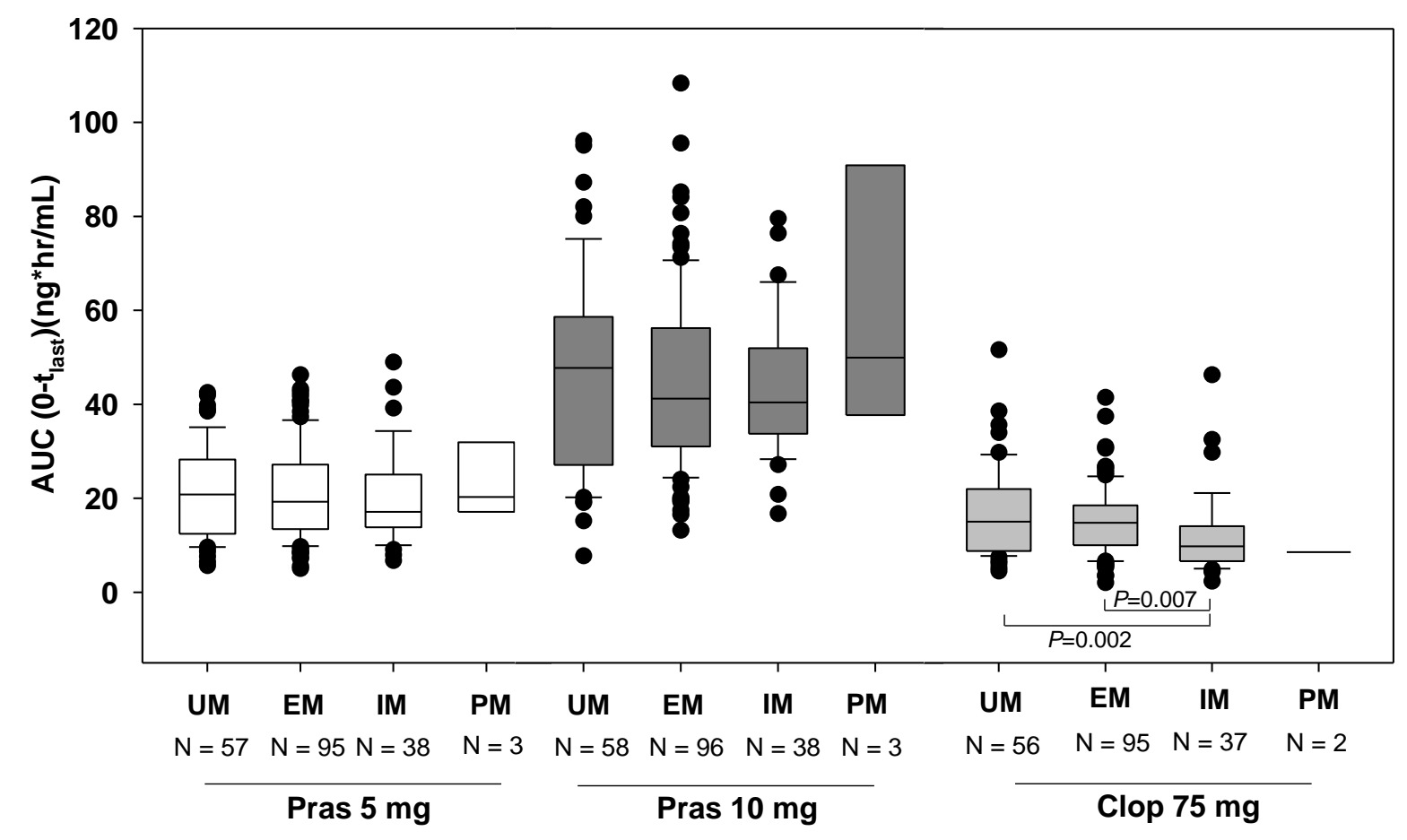


Figure S2. Pharmacodynamic response to clopidogrel 75-mg and prasugrel 5-mg and 10mg according to four level CYP2C19-predicted metabolizer status as measured by (A) VASP-PRI; (B) VerifyNow-PRU; or (C) MPA to $20 \mu \mathrm{M}$ ADP by light transmission aggregometry. Between predicted metabolizer group comparisons, statistical significance $\mathrm{p} \geq 0.05$ unless shown on figure; statistical significance for comparisons versus PM, data not shown due to low sample size.

$\mathrm{UM}=$ ultrametabolizers; $\mathrm{EM}=$ extensive metabolizers; $\mathrm{IM}=$ intermediate metabolizers; $\mathrm{PM}=$ poor metabolizers; Pras $=$ prasugrel; Clop $=$ clopidogrel; VASP-PRI $=$ vasodilator - stimulated phosphoprotein platelet reactivity index; VN-PRU = VerifyNow P2Y12 reaction units; MPA = maximum platelet aggregation measured by light transmission aggregometry; $\mathrm{ADP}=$ adenosine diphosphate

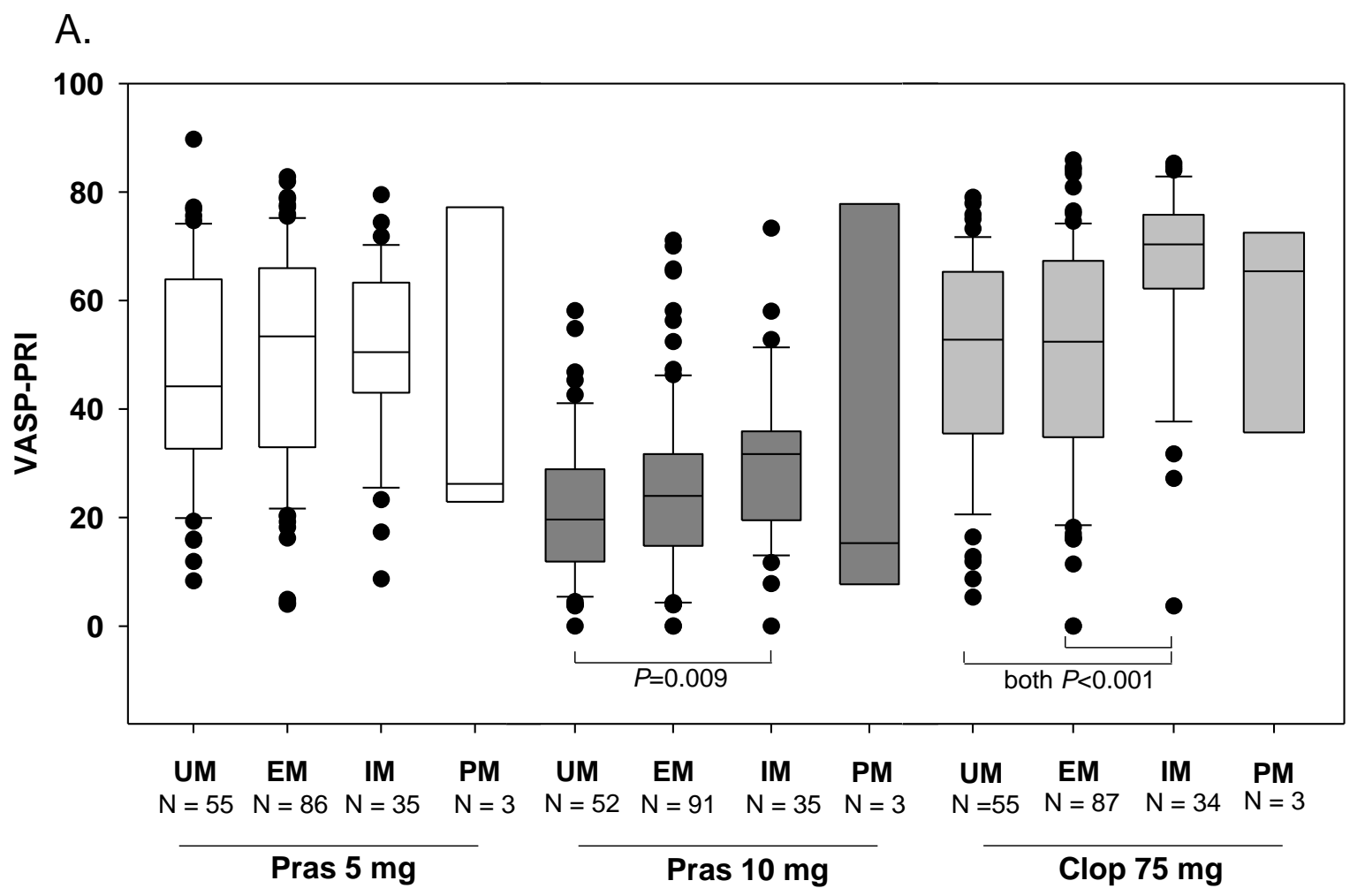


B.

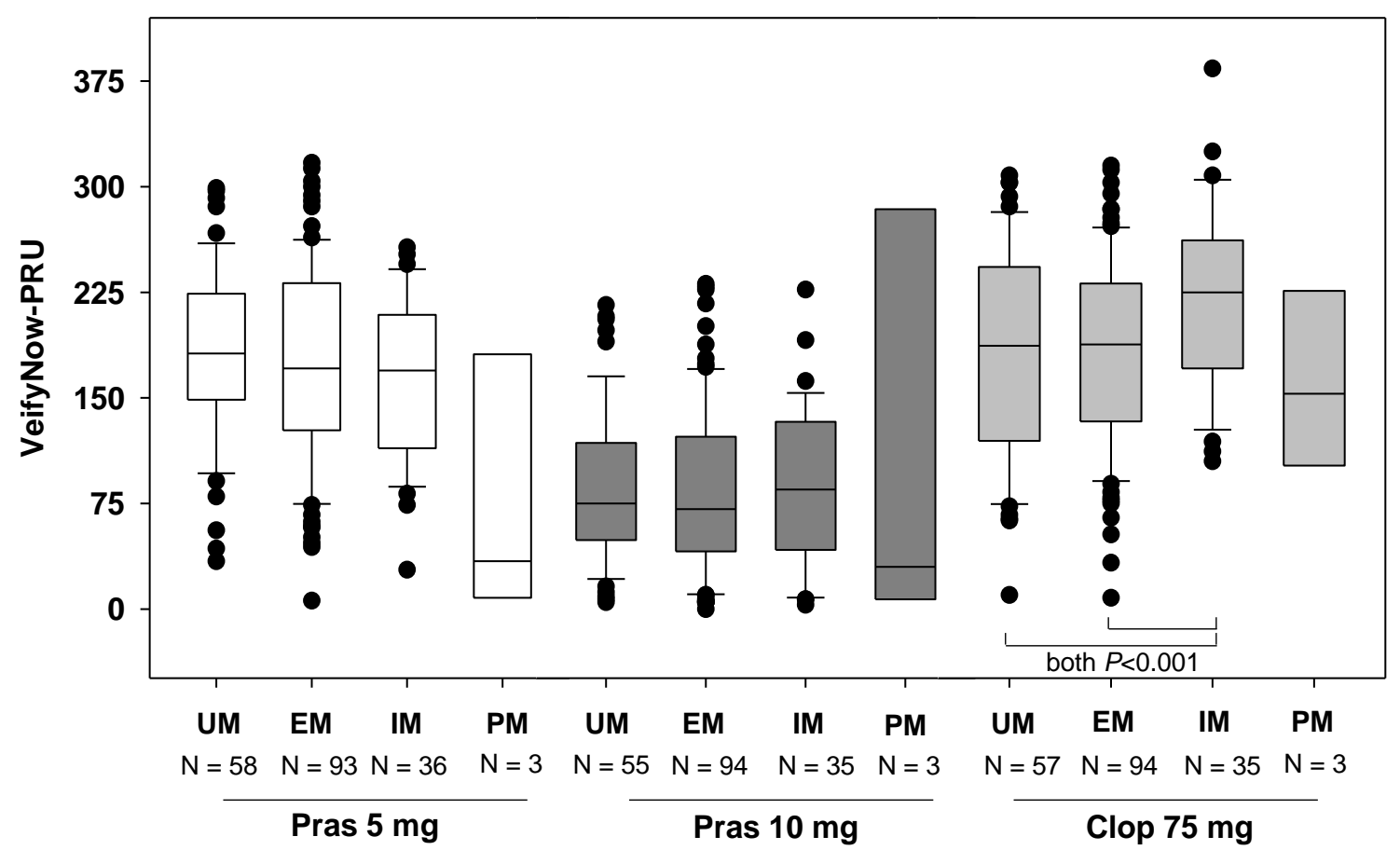

c.

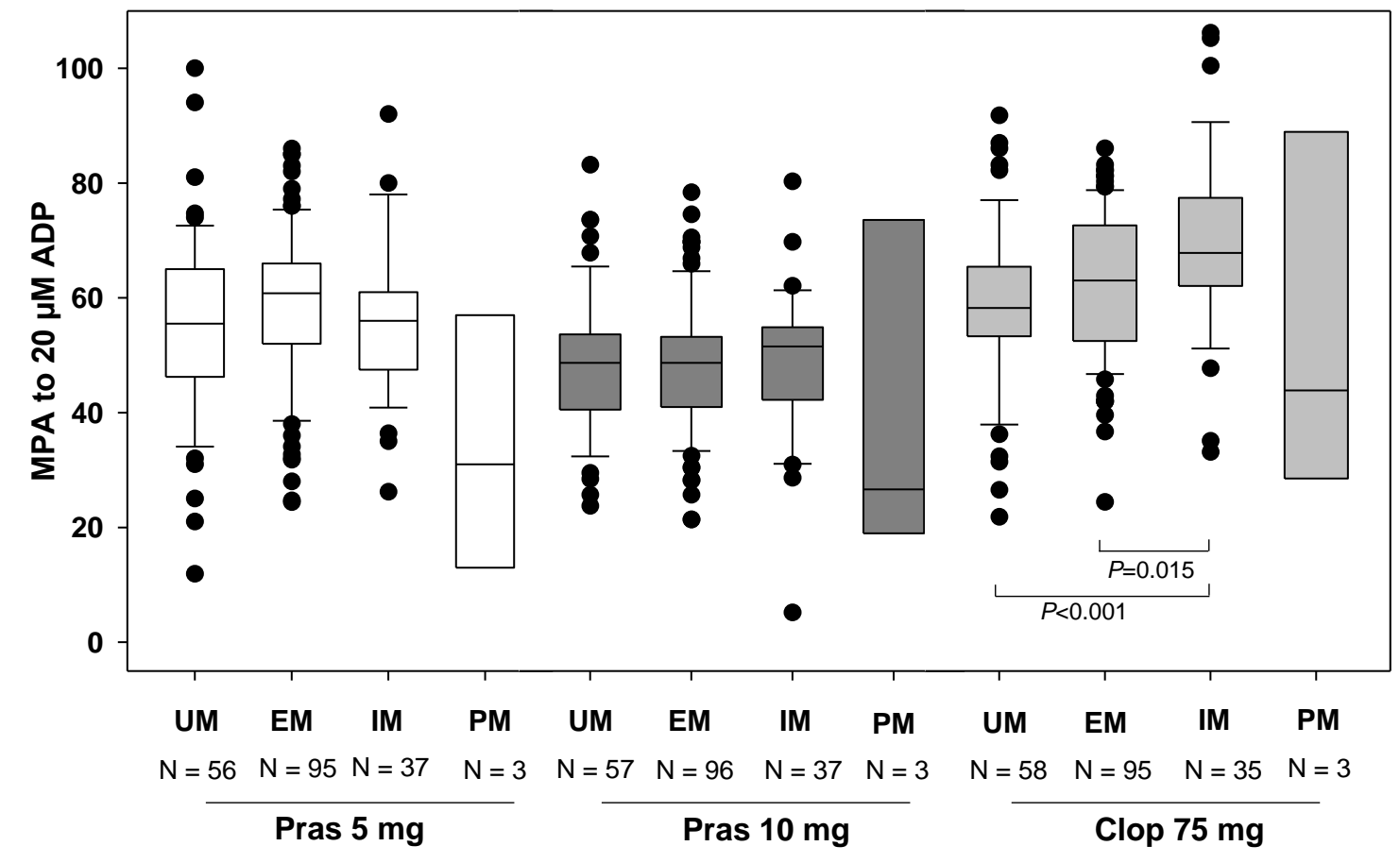

